\title{
Thyroid Function Disorders among the Indian Population
}

\begin{abstract}
Maurya $\mathbf{H}^{*}$
Department of Pharmacology, Hygia Institute of

Pharmaceutical Education and Research, India

*Corresponding author: Maurya H, Hygia Institute of Pharmaceutical Education and Research, Prabandh Nagar, Lucknow, Utter Pradesh, India
\end{abstract}

Received: October 25, 2018; Accepted: November 26, 2018; Published: December 06, 2018

\section{Abstract}

Thyroid disorders are one of the commonest disease producing significant burden in India and worldwide. According to the clinical survey from various studies on thyroid disease, it has been estimated that about $32 \%$ of people suffer from thyroid diseases in India. Maximum cases of hypothyroidism have been reported from people living in the Northern regions as compared to the rest of the country. The early critical diagnosis and complete treatment with appropriate medications can be successfully managed.

Keywords: Thyroid; Hypothyroidism; Hyperthyroidism; India; Metabolism

\section{Introduction}

Thyroid diseases are questionable along with the commonest endocrine disorders worldwide in which hypothyroidism is supposed to be a common health problem in India. Thyroid hormones control metabolism, growth, body temperature, menstrual cycles, the functioning of the lungs, heart \& muscle strength and ancillary vital organs [1].

The thyroid is a small, butterfly-shaped gland located near throat synthesizes and secretes mainly two hormones i.e., $\mathrm{T}_{4}$ (Thyroxine) and $\mathrm{T}_{3}$ (Triiodothyronine) [2]. TSH stands for thyroid stimulating hormone, which is produced by the pituitary gland of the brain. This gland stimulates the thyroid to synthesize and release the thyroid hormones into the blood.

Thyroid disorder is a silent disease where the symptoms are subtle and may be often overlooked during diagnosis, so it's essential to critical monitoring during such type of diagnosis. Generally, the symptoms of the under-active thyroid are similar in men as well as in women, with weakness, fatigue, weight gain, depression and high cholesterol dominancy [3]. The commonest symptoms of Hypothyroidism and Hyperthyroidism are mentioned as follows (Figure 1\&2); Iodine is an essential micronutrient required for normal thyroid function, growth and development. Iodine deficiency is the single most important and preventable cause of mental retardation worldwide. During pregnancy, recommended dietary allowance of iodine is increased by $50 \%$ due to Physiological increase in maternal and fetal thyroid hormone production and Increase in renal iodine losses [4].

In India sub-Himalayan region especially from Kashmir to Assam is the well-recognized area of endemic iodine deficiency. Despite the coverage of national iodine deficiency control program in India, iodine deficiency is still prevalent in many parts of India [5].

A clinical survey recorded that North India has the maximum cases of hypothyroidism, a condition in which thyroid gland cannot make enough hormone to keep the body running. The analysis is based on in-house data collected from over 33 lakh adults pan-India revealed where all three thyroid panel markers, viz. TSH, $\mathrm{T}_{4}$, and $\mathrm{T}_{3}$ included producing a comprehensive data analysis, out of which $68 \%$ of reports were normal and about $32 \%$ of the Indian population is suffering from different kinds of thyroid disorders including thyroid

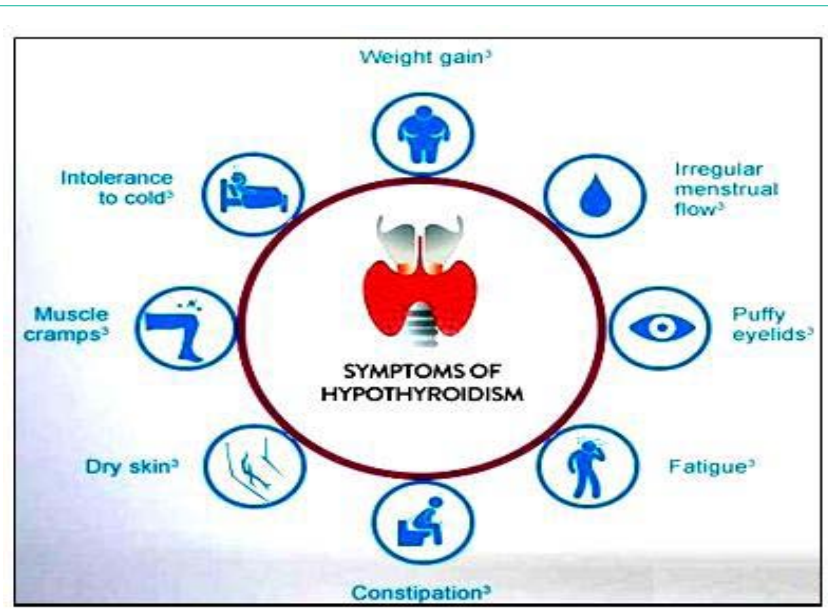

Figure 1: Hypothyroidism: A condition in which the thyroid gland produces lesser than the required quantity of thyroid hormone [3]

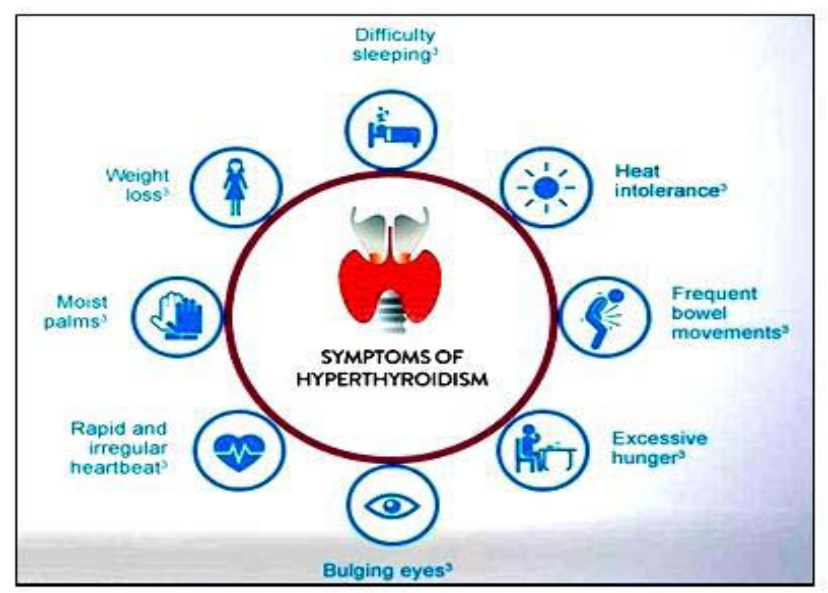

Figure 2: Hyperthyroidism: A condition in which excessive thyroid hormone is produced [3].

nodules, hyperthyroidism, goiter, thyroiditis and thyroid cancer [6].

The milder form of hypothyroidism where the diagnosis is made unexpectedly emerged as the most prevalent form of thyroid disorder
Annals Thyroid Res - Volume 4 Issue 3 - 2018

Submit your Manuscript | www.austinpublishinggroup.com

Maurya. () All rights are reserved
Citation: Maurya $\mathrm{H}$. Thyroid Function Disorders among the Indian Population. Annals Thyroid Res. 2018; 4(3): 172-173. 
across the country with maximum cases being present in the eastern part of the Indian countries. Despite the fact that thyroid dysfunction was common in young women in south India region. The report says that one out of every eight young women had thyroid dysfunction, whether mild TSH elevation was the most common abnormality [7].

In the post iodization era, a study was conducted to analyze the thyroid hormone levels among adult non-pregnant women of Jharkhand region, which is traditionally known to be an iodinedeficient area. This is the first study in Jharkhand area on the nonpregnant adult female population that is getting iodine sufficient foods in an iodine-deficient region. The study showed a high prevalence of thyroid disorders in the study group. Hypothyroidism, predominantly subclinical hypothyroidism, is prevalent among women in this region [8].

A clinical survey designed to study the disease profile and treatment paradigm in hypothyroid patients in India. Appropriate treatment of hypothyroidism requires accurate diagnosis. Guidelines suggest a diagnosis of hypothyroidism based on TSH and $\mathrm{T}_{4}$ levels. However, most of the patients as observed in this registry received treatment with levothyroxine based on TSH levels alone, thus highlighting the need for awareness and scientific education among clinicians in India. The use of standard doses of levothyroxine (100, 75 , and $25 \mathrm{mcg}$ ) may point toward empirical management practices [9].

A good diet consisting of iodine-rich foods, protein, eggs, probiotics like yogurt and healthy fats such as cow-milk fat that help to manage in balancing hormones. Genetics plays a crucial role in both determination of thyroid hormones and TSH concentrations, and susceptibility to autoimmune thyroid disease. People who have a history of thyroid problems in their family would be predisposed to thyroid abnormalities [10].

\section{Conclusion}

According to the clinical survey, more than one third of the India population suffers from thyroid disorders, that means about $32 \%$ Indians have suffered various forms of thyroid disorders. Symptoms of underactive thyroid (hypothyroidism) are similar in men as well as women that included weakness, fatigue, weight gain, depression, and high cholesterol level. Overactive thyroid (hyperthyroidism) is a condition in which the thyroid gland produces too much of the hormone thyroxin that can accelerate metabolism significantly, causing sudden weight loss, a rapid or irregular heartbeat, sweating, and nervousness or irritability. Maximum cases of hypothyroidism have been reported from people living in the Northern regions as compared to the rest of the Indian countries. With early diagnosis and treatment, the thyroid can be successfully managed. Hormone replacement is a safe and effective treatment that can manage one's symptoms and prevent complications.

\section{References}

1. Jameson J, Weetman A, Fauci A, Braunwald E, Kasper D, Hauser S, et al. Disorders of the thyroid gland. Harrison's Principles of Internal Medicine. $17^{\text {th }}$ edition. USA: The McGraw Hill Companies Inc. 2008: 2224-2247.

2. Marieb E, Hoehn K. Regulation and integration of the body. The endocrine system. Human Anatomy and Physiology. $7^{\text {th }}$ edition. San Francisco, CA: Pearson Education Inc. 2007: 620-625.

3. Braverman LE, Utiger RD, Eds. Werner \& Ingbar's The Thyroid: A Fundamental and Clinical Text. $8^{\text {th }}$ edition. Philadelphia, Pa: Lippincott, Williams \& Wilkins. 2000: 837-838.

4. Sareen N, Kapil U. lodine Deficiency amongst Vulnerable Population of Endemic Districts of India. J Endocrinol Thyroid Res. 2017; 2: 01-06.

5. Bania D, Das K. A Study on prevalence of thyroid function disorders amongst the population of Barpeta district, Assam. J Dent Med Sci. 2017; 16: 47-50.

6. Unnikrishnan AG, Menon UV. Thyroid disorders in India: An epidemiological perspective. Ind J Endo Metab. 2011; 15: S78-S81.

7. Velayutham K, Selvan SSA, Unnikrishnan AG. Prevalence of thyroid dysfunction among young females in a South Indian population. Indian J Endocrinol Metab. 2015; 19: 781-784.

8. Chakrabarty BK, Mitra B, Shahbabu B, Hazra N, Singh S. Thyroid Function Status in Indian Adult Nonpregnant Females in Ranchi, India. Indian J Med Biochem. 2017; 21: 25-29.

9. Sethi B, Barua S, Raghavendra M S, Gotur J, Khandelwal D, Vyas U. The thyroid registry: Clinical and hormonal characteristics of adult Indian patients with hypothyroidism. Indian J Endocr Metab. 2017; 21: 302-327.

10. Brahmbhatt SR, Brahmbhatt RM, Boyages SC. Impact of protein-energy malnutrition on thyroid size in an iodine deficient population of Gujarat (India): Is it an aetiological factor for goiter?. Eur J Endocrinol. 2001; 145: 11-17.
Annals Thyroid Res - Volume 4 Issue 3 - 2018

Submit your Manuscript | www.austinpublishing group.com Maurya. (C) All rights are reserved
Citation: Maurya $\mathrm{H}$. Thyroid Function Disorders among the Indian Population. Annals Thyroid Res. 2018; 4(3): 172-173. 